Check for updates

Cite this: J. Mater. Chem. A, 2018, 6 , 10264

Received 5th March 2018 Accepted 26th April 2018 DOI: $10.1039 / c 8 t a 02083 c$ rsc.li/materials-a

\section{The impact of non-uniform photogeneration on mass transport in dye-sensitised solar cells $\uparrow$}

\begin{abstract}
Roger Jiang (D) and Gerrit Boschloo (D) *
Following the introduction of cobalt(॥/II)tris(2,2'-bipyridyl)-based redox mediators, dye-sensitised solar cells (DSSCs) have greatly advanced in power conversion efficiency (PCE). However, significant limiting factors include the fast electron recombination and slow mass transport of the oxidised redox mediator $\left(\left[\mathrm{Co}(\text { bipy })_{3}\right]^{3+}\right)$. In this work, the effect of non-uniform photogeneration on the mass transport of $\left[\mathrm{Co}(\text { bipy })_{3}\right]^{3+}$ through an electrolyte-infiltrated mesoporous $\mathrm{TiO}_{2}$ film was investigated. Different illumination conditions were used to control the photogeneration profile and the subsequent spatial distribution of $\left[\mathrm{Co}(\text { bipy) })_{3}\right]^{3+}$ throughout the $\mathrm{TiO}_{2}$ film. They included parameters such as the light intensity, substrate-electrode/electrolyte-electrode (SE/EE) illumination direction, wavelength, and $\mathrm{TiO}_{2}$ photoanode thickness. Using large and small optical perturbation photocurrent transients, electron recombination kinetics with $\left[\mathrm{Co}(\text { bipy })_{3}\right]^{3+}$ were analysed in the time domain. Importantly, strong SEabsorption was shown to significantly contribute to the gradual depletion of $\left[\mathrm{Co}(\mathrm{bipy})_{3}\right]^{3+}$ at the counter electrode, along with an increased film thickness and light intensity, resulting in excess recombination with $\left[\mathrm{Co}(\text { bipy })_{3}\right]^{3+}$ on the $10^{-2}-1 \mathrm{~s}$ timescale. Furthermore, charge extraction current decay transients showed that a substantial amount of $\left[\mathrm{Co}(\text { bipy })_{3}\right]^{3+}$ can accumulate inside the $\mathrm{TiO}_{2}$ film, resulting in significant recombination at the collecting fluorine-doped tin oxide (FTO) contact on the $10^{-3}-10^{-2} \mathrm{~s}$ timescale. The sub-linear scaling of recombination with light intensity leads to deviating trends in charge extraction and electron transport measurements. Mass transport limitations and recombination losses at the FTO can be significantly reduced by maximising light absorption from the EE-side, which can increase PCE and reduce $J-V$ hysteresis.
\end{abstract}

\section{Introduction}

Dye sensitised solar cells (DSSCs) have promising potential for low cost photovoltaic energy conversion. ${ }^{\mathbf{1}, 2}$ The state of the art DSSCs have reached record power conversion efficiencies (PCE) of $12-14.3 \% .^{3-5}$ This recent breakthrough in DSSC efficiency followed the introduction of alternative cobalt polypyridine redox mediators, ${ }^{6-8}$ which supersede the previous standard iodide/triiodide redox system. Some significant improvements include the greatly enhanced open-circuit voltage, ${ }^{3,9,10}$ the reduced competitive light absorption from the electrolyte, ${ }^{7,8,11}$ and the reduced tendency to corrode metal components. ${ }^{7,12,13}$ However, these advantages come with the trade-offs of faster electrolytic recombination ${ }^{\mathbf{6 , 8 , 1 2}}$ and up to one order of magnitude lower diffusion coefficient. ${ }^{\mathbf{8 1 4}}$ Therefore, substantial effort has been made to improve the mass transport of the redox mediator, for instance, by reducing the redox mediator bulkiness, ${ }^{\mathbf{8 , 1 4}}$ increasing the redox mediator concentration, ${ }^{\mathbf{1 4}-17}$

Address Department of Chemistry, Angström Laboratory, Uppsala University, Box 523, SE-75120, Uppsala, Sweden.E-mail: roger.jiang@protonmail.com; gerrit.boschloo@ kemi.uu.se

$\dagger$ Electronic supplementary information (ESI) available. See DOI: $10.1039 / \mathrm{c} 8 \mathrm{ta0} 2083 \mathrm{c}$ increasing the $\mathrm{TiO}_{2}$ porosity, ${ }^{\mathbf{1 8 - 2 1}}$ reducing the $\mathrm{TiO}_{2}$ film thickness, ${ }^{\mathbf{8}, 16,17}$ reducing the inter-electrode distance, ${ }^{\mathbf{1 1}, 16}$ heating of the electrolyte, ${ }^{22,23}$ and reducing the electrolyte viscosity. ${ }^{\mathbf{1 4 , 2 0}}$ Unfortunately, such optimisation has mainly been confined to highly flammable, volatile and toxic acetonitrile-based electrolytes, which, despite yielding record efficiencies on paper, are unsurprisingly unrealistic for commercialisation. More pressingly, little progress has been made to replace the iodide/ triiodide redox system for robust electrolyte DSSCs. On the other hand, high stability devices engineered with more viscous and robust electrolytes perform much worse, primarily due to mass transport limitations of the redox mediator. Thus, it is important to better understand how the devices can become mass transport limited and develop strategies to circumvent this issue. Specifically, in this work, the effect of the absorption profile across the mesoporous $\mathrm{TiO}_{2}$ photoanode is investigated with respect to mass transport. Typically, DSSCs require strongly absorbing sensitisers or thicker sensitised films, in order to maximise light harvesting. However, the light absorption profile also affects the subsequent spatial distribution of oxidised redox mediators, and in particular, within the electrolyte-infiltrated $\mathrm{TiO}_{2}$ film. Critically, this could contribute to mass transport limitations, given that redox mediator 
diffusion is significantly lower in the electrolyte-infiltrated $\mathrm{TiO}_{2}$ relative to the bulk electrolyte. ${ }^{15}$

The aim of this work is to critically study the factors contributing to device operating limitations and to develop strategies for improving mass transport, in order to shift away from volatile acetonitrile-based electrolytes. Despite the excellent photostability of cobalt-based electrolytes, ${ }^{15,16,24}$ electrolyte solvent leakage remains a critical issue for the long-term operating stability. ${ }^{15,25}$ Thus far, there has been substantial effort to increase the stability of DSSCs, with respect to sealing the electrolyte inside the device, for instance, through the use of electrolytic gelling agents, ${ }^{26-28}$ polymer electrolytes, ${ }^{29-32}$ and ionic liquids. ${ }^{33-36}$ Unfortunately, these methods significantly reduce redox mediator diffusion and thus the device performance, especially for bulkier redox mediators. In this work, various photogeneration profiles were investigated by controlling the direction of the illumination source facing the device, ${ }^{37-39}$ the wavelength of the illumination source, ${ }^{40}$ and the $\mathrm{TiO}_{2}$ photoanode thickness. The combination of higher light intensities, strongly absorbed wavelengths and thicker films can be used to simulate more extreme cases of mass transport limitation. This can be compared to other similar DSSC devices, in terms of equivalent photocurrent density output. Overall, this work is especially relevant to the development of more stable albeit inherently mass transport limited DSSCs, which remains a substantial portion of ongoing DSSC research. Nevertheless, the understanding of operating limitations should be broadly relevant to electrolytic DSSCs.

\section{Experimental}

\subsection{Materials and chemicals}

All chemicals were purchased from Sigma Aldrich unless otherwise stated. Fluorine doped $\mathrm{SnO}_{2}$ (FTO) glass substrates (TEC15 and TEC8) were purchased from Pilkington. $\mathrm{TiO}_{2}$ paste (DSL 18NR-T and DSL 30NR-D) was purchased from Dyesol. Cobalt(II/III)tris(2,2'-bipyridyl) (denoted hereafter as $\left[\mathrm{Co}(\text { bipy })_{3}\right]^{2+/ 3+}$ ) with hexafluorophosphate counterions was purchased from Dyenamo. LEG4 dye (DN-F05) was purchased from Dyenamo; the full chemical name of LEG4 is $3-\left\{6-\left\{4-\left[\operatorname{bis}\left(2^{\prime}, 4^{\prime}-\right.\right.\right.\right.$ dibutyloxybiphenyl-4-yl)amino-]phenyl $\}$-4,4-dihexyl-cyclopenta-

[2,1-b:3,4-b'] dithiophene-2-yl\}-2-cyanoacrylic acid.

\subsection{Device fabrication}

Fluorine doped tin oxide (FTO) glass substrates were cleaned using detergent, de-ionised water and ethanol. Working electrodes were prepared with an initial $\mathrm{TiCl}_{4}$ treatment; the TEC15 FTO substrates were heated in $40 \mathrm{mM} \mathrm{TiCl}_{4}$ aqueous solution at $70{ }^{\circ} \mathrm{C}$ for $1.5 \mathrm{~h}$, and then sintered for $30 \mathrm{~min}$ at $500{ }^{\circ} \mathrm{C} . \mathrm{TiO}_{2}$ films were screen printed onto the substrates using Dyesol 18NR-T $\mathrm{TiO}_{2}$ paste and $5 \times 5 \mathrm{~mm}(120 \mathrm{~T})$ screen printing meshes, and then sintered again. A final $\mathrm{TiCl}_{4}$ treatment was repeated for $30 \mathrm{~min}$, followed by sintering. Finally, the substrates were cooled down to $120{ }^{\circ} \mathrm{C}$, immersed in dye bath solution ( 0.2 mM LEG4 in $1: 1$ tert-butanol : acetonitrile $\mathrm{v} / \mathrm{v})$ for $16 \mathrm{~h}$, and then rinsed in acetonitrile. Counter electrodes were prepared by spreading $5 \mathrm{mM} \mathrm{H}_{2} \mathrm{PtCl}_{6}$ solution onto TEC8 FTO substrates, followed by heating at $400{ }^{\circ} \mathrm{C}$ for $30 \mathrm{~min}$. Respective electrodes were sandwiched together via a Surlyn thermoplastic (Meltonix 1170-25, Solaronix), using a hot-press (Heptachroma) heated to $125{ }^{\circ} \mathrm{C}$ whilst applying 0.2 bar for $60 \mathrm{~s}$, resulting in a spacing between the two FTO electrodes of approximately 20 $\mu \mathrm{m}$. Electrolyte solution was injected through a pre-drilled hole on the counter electrode, and then sealed with Surlyn and a glass coverslip. The electrolyte consisted of $0.22 \mathrm{M} \mathrm{Co}(\mathrm{bipy})_{3}\left(\mathrm{PF}_{6}\right)_{2}$, $0.04 \mathrm{M} \mathrm{Co}(\text { bipy })_{3}\left(\mathrm{PF}_{6}\right)_{3}, 0.1 \mathrm{M} \mathrm{LiClO}_{4}$ and $0.2 \mathrm{M}$ 4-tert-butylpyridine (TBP) in acetonitrile (ACN). $\mathrm{TiO}_{2}$ photoanode thicknesses were measured by using a profilometer (Veeco Dektak 3). $\mathrm{TiO}_{2}$ photoanode thicknesses ranged from 6.5 to $19.5 \mu \mathrm{m} \pm 0.2 \mu \mathrm{m}$, which corresponds to the bulk electrolyte thickness ranging from 13.5 to $0.5 \mu \mathrm{m}$. UV-vis absorption was measured using a Varian Cary 5000 spectrometer. For UV-vis measurements, a $3.5 \mu \mathrm{m}$ LEG4-sensitised film (18NR-T) was measured in air. Absolute irradiance spectra were measured using a UV-vis spectrometer (HR2000, Ocean Optics) fitted with a cosine corrector (CC-3-UV, Ocean Optics), which was calibrated using a reference halogen light source (DH-2000-CAL, Ocean Optics).

In a follow-up experiment, additional $6.5 \mu \mathrm{m} \mathrm{\textrm {TiO } _ { 2 }}$ films were prepared to compare the effect of different FTO blocking layers: (a) with $\mathrm{TiCl}_{4}$ pre-treatment, (b) without $\mathrm{TiCl}_{4}$ pre-treatment, and (c) with a compact $\mathrm{TiO}_{2}$ blocking layer prepared following a spray pyrolysis method. ${ }^{15}$

\subsection{Device characterisation}

Measurements were made under white LED (WLED) illumination (Bridgelux, BXRC-27G10K0-L-03) and maintained at $25{ }^{\circ} \mathrm{C}$ (WLED colour spectrum shown in Fig. 2a and S1b $\dagger$ ). The illumination intensity was further concentrated by using an aspheric Fresnel lens (46-389, Edmund Optics). This enables higher light intensity from a greater distance, which minimises the amount of heat output from the LED reaching the cell. Both the LED and cell were mounted on fan-cooled heatsinks to maximise cooling. This enabled the cells to be kept at $25{ }^{\circ} \mathrm{C}$, even under high intensity illumination. Importantly, this excludes temperature as a variable from the experiment, which can significantly affect mediator diffusion and PCE. ${ }^{41,42}$ The light intensity of the WLED was calibrated to produce the same photocurrent, using a certified reference Si cell (Fraunhofer ISE), as measured under AM 1.5 solar simulator illumination (Newport). Therefore, we can compare equivalent "sun" intensities, in terms of the photon flux density. Band-pass filters were used in conjunction with the WLED to vary the relative wavelength output (transmission spectra of filters and absolute irradiance spectrum of WLED with filters, shown in Fig. S1a $\dagger$ and $2 \mathrm{a}$, respectively). For brevity, the relative illumination wavelengths are hereon referred to as "blue", "green", "white" and "red" (white refers to the unfiltered WLED source). Our setup was capable of sustaining 2 suns intensity red band-pass filtered illumination, which required an equivalent of 8.765 sun unfiltered white LED illumination. The cells were measured with a $5 \times 5 \mathrm{~mm}$ black anodised aluminium mask.

Fig. 1 illustrates the entirety of the measurement procedure used in this study. A series of large and small optical 
(a)

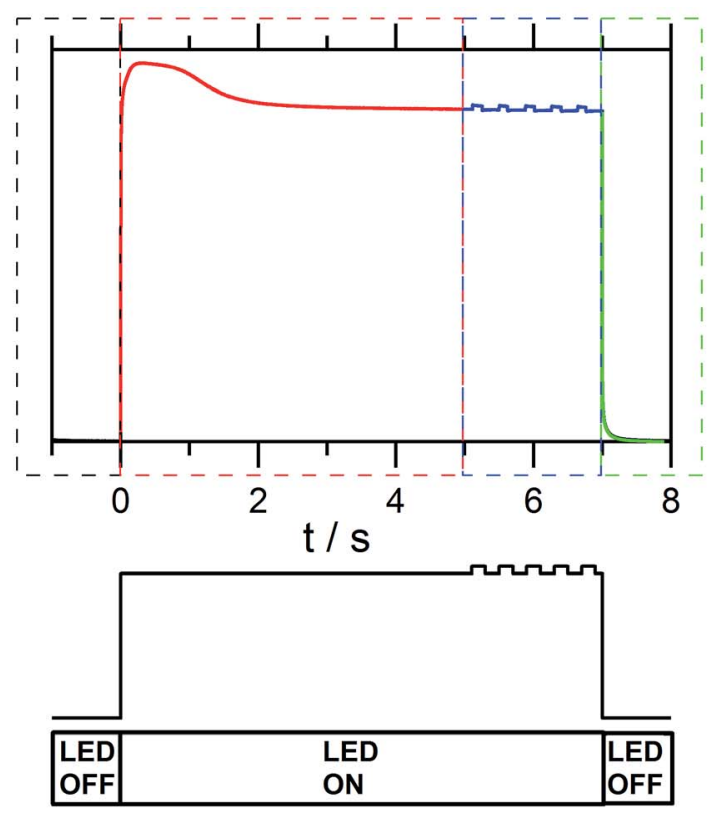

(b)

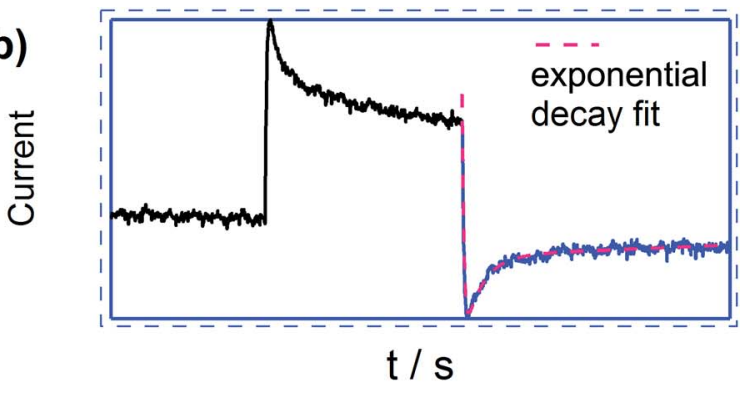

(c)

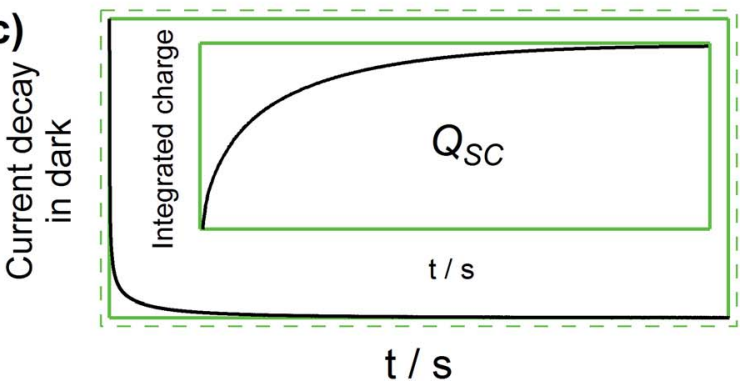

Fig. 1 Example of the data acquisition sequence. Sections of the waveform are coloured for illustrative purposes. (a) Photocurrent rise transients (red) and charge extraction transients (green) obtained by switching light on and off, respectively. (b) Small perturbation current decay transients (blue) obtained following small optical perturbations under steady-state illumination. (c) Charge extraction current decay transient and cumulative charge integral.

perturbations were applied to the cell, and the short circuit photocurrent response was acquired as a function of time. Photocurrent transients are simple and quick to measure; each photocurrent transient measurement was acquired within $\sim 10 \mathrm{~s}$, and the total acquisition time for all the data presented in this study (excluding repeats) was $\sim 42$ min. Shorter measurements have the advantage of minimising light exposure, which reduces the potential for drift or degradation, improving measurement accuracy and repeatability. In general, this method can be useful for the screening of other less photostable devices.

The photocurrent transient measurements were performed under short-circuit conditions. Ultrafast solid-state switches were used to control power delivery to the LEDs and timed using a DAQ (NI-6211 and NI-6703, National Instruments). Light intensity and optical modulations were applied by using a programmable power supply (CPX400DP, Thurlby Thandar Instruments). Photocurrent rise transients (Fig. 1a, red) were obtained by measuring the photocurrent response (at shortcircuit and $25{ }^{\circ} \mathrm{C}$ ), following dark to illumination. Next, after $5 \mathrm{~s}$ of illumination, a series of small optical perturbations were applied (Fig. 1a and b, blue) as a square wave pulse ( $0.1 \mathrm{~s}$ on, $0.4 \mathrm{~s}$ off). The modulation pulse intensity was maintained at $5-$ $2 \%$ of the stand-by sun intensity; greater perturbations were required at lower intensities in order to improve the signal-tonoise ratio. Finally, after $7 \mathrm{~s}$, the light was switched off, whilst simultaneously measuring the photocurrent decay transient (Fig. 1a and c, green) for $1 \mathrm{~s}$ in the dark. The subsequent current decay transient in the dark was integrated to estimate the amount of excess charge density stored inside the $\mathrm{TiO}_{2}$ photoanode $\left(Q_{\mathrm{SC}}\right){ }^{43,44}$ Charge density was calculated assuming a bulk
$\mathrm{TiO}_{2}$ volume ratio of $45 \%$, and $Q_{\mathrm{SC}}$ units are shown as the number of electrons per cubic centimetre $\left(\mathrm{e} \mathrm{cm}^{-3}\right)$.

\section{Results and discussion}

\subsection{Cross-sectional absorption profile}

Fig. 2a shows the UV-vis absorption spectrum of a LEG4sensitised photoanode, which exhibits a broad absorption peak around $460 \mathrm{~nm}$. Table 1 lists the decadic attenuation constant $(\alpha)$ and the light penetration depth $\left(\delta_{\mathrm{p}}\right)$, calculated using absorbance values from Fig. 2a, at various wavelengths. From 460 to $660 \mathrm{~nm}, \delta_{\mathrm{p}}$ values range from 1.8 to $34.7 \mu \mathrm{m}$. In comparison, high efficiency DSSCs typically have photoanode thicknesses ranging between 5 and $10 \mu \mathrm{m}$. Unsurprisingly, DSSCs with strongly absorbing sensitisers tend to absorb less uniformly across the photoanode. Fig. $2 \mathrm{~b}$ illustrates the exponential attenuation of monochromatic light across the sensitised photoanode. Importantly, this affects the electron photogeneration profile which is proportional to light absorption throughout the photoanode. ${ }^{37,43}$ Additionally, the direction of illumination can be varied, with the illumination source facing either the substrate-electrode (SE) or electrolyte-electrode (EE). These parameters can be used to qualitatively control the photogeneration profile, and the subsequent spatial distribution of injected electrons in $\mathrm{TiO}_{2}$ and $\left[\mathrm{Co}(\text { bipy })_{3}\right]^{3+}$ in the electrolyte. This changes the average diffusion distance for the respective charge carriers, which is illustrated in Fig. 3. For instance, strong SE-absorption (i.e., SE-blue) should generate more $\left[\mathrm{Co}(\text { bipy })_{3}\right]^{3+}$ closer to the SE-side, which would increase the average diffusion distance of $\left[\mathrm{Co}(\mathrm{bipy})_{3}\right]^{3+}$ to the counter electrode. Conversely, more uniform SE-absorption (i.e., SE-red) 
(a)

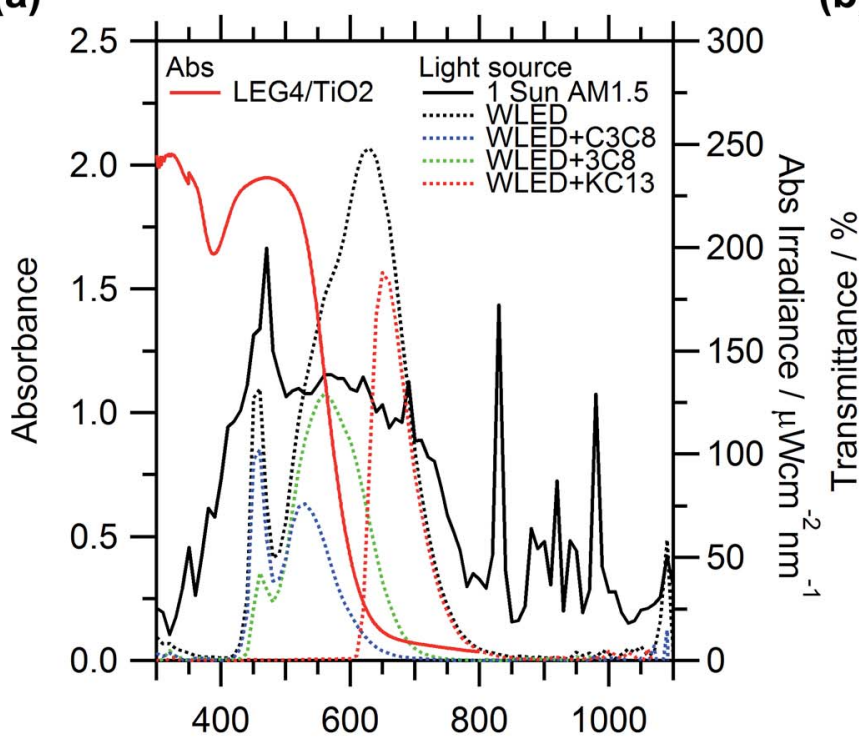

$\lambda / \mathrm{nm}$ (b)

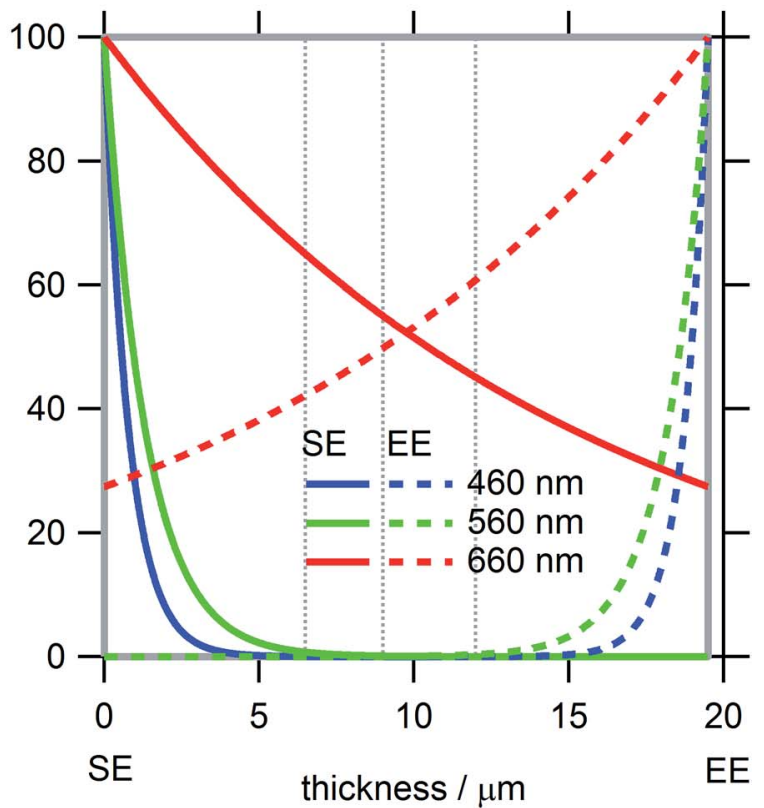

Fig. 2 (a) UV-vis absorption spectrum of a $3.5 \mu \mathrm{m}$ LEG4-sensitised $\mathrm{TiO}_{2}$ film measured in air. Comparison of the irradiance spectrum of light sources; comparison of WLEDs with band-pass filters. (b) Transmittance of various wavelengths through the cross section of the LEG4-sensitised $\mathrm{TiO}_{2}$ film, approximated using the Beer-Lambert law, assuming uniform attenuation. Comparison of SE/EE-illumination directions (solid/dashed lines). Photoanode thicknesses ranging from 6.5 to $19.5 \mu \mathrm{m}$ are shown (grey lines).

or strong EE-blue absorption should generate more $\left[\mathrm{Co}(\text { bipy })_{3}\right]^{3+}$ closer to the EE-side, which would decrease the average diffusion distance to the counter electrode.

Some caveats should be noted. Firstly, band-pass filtered LED illumination was used, rather than a monochromatic source, for ease of implementation. Nevertheless, the discussion above remains relevant as the relative absorption profiles can still be compared. Secondly, a uniform photoanode was required to fairly compare $\mathrm{SE} / \mathrm{EE}$-illumination directionality. Therefore, $\mathrm{TiO}_{2}$ films were prepared as a transparent $\mathrm{TiO}_{2}$ layer. Typically, in high performance devices, an additional $\mathrm{TiO}_{2}$ scattering layer is added to increase the photocurrent. ${ }^{45,46}$ As such, the devices in this study produce less current than typically expected. Also, Fig. 2 shows that there is a substantial spectral mismatch of the WLED versus AM 1.5; the current measured using WLEDs was $>20 \%$ lower when compared to AM 1.5 irradiance. To demonstrate that the findings in this study are broadly relevant to electrolytic DSSCs, a repeat set of measurements based on AM 1.5 characterised high efficiency DSSCs is included in the ESI (Fig. S10-1X $\dagger$ ). These additional

Table 1 Light penetration depth of monochromatic blue (460 nm), green $(560 \mathrm{~nm})$ and red $(660 \mathrm{~nm})$ light travelling through the LEG4 sensitised photoanode

\begin{tabular}{llll}
\hline$\lambda / \mathrm{nm}$ & $\begin{array}{l}\text { Absorbance } \\
(A)\end{array}$ & $\begin{array}{l}\text { Attenuation constant } \\
(\alpha) / \mathrm{m}^{-1}\end{array}$ & $\begin{array}{l}\text { Penetration } \\
\text { depth }\left(\delta_{\mathrm{p}}\right) / \mu \mathrm{m}\end{array}$ \\
\hline 460 & 1.94 & $5.56 \times 10^{5}$ & 1.80 \\
560 & 1.15 & $3.30 \times 10^{5}$ & 3.03 \\
660 & 0.10 & $2.88 \times 10^{4}$ & 34.70
\end{tabular}

results fully replicate the trends presented in this manuscript, which shows that the lower current of the devices does not affect the conclusion. Thirdly, unlike iodide-based electrolytes, the absorption losses to the electrolyte under EE-illumination are relatively minor, given that $\left[\mathrm{Co}(\text { bipy })_{3}\right]^{2 / 3+}$ is weakly absorbing. ${ }^{7,8,11}$ The uniformity and transparency of Pt electrodes can affect transmission losses for EE-side illumination. Overall, up to an $\sim 10 \%$ optical transmission loss in the $300-700 \mathrm{~nm}$ range for the back electrode relative to the front electrode (ESI Fig. S9†) was observed. EE-illuminated devices tend to exhibit

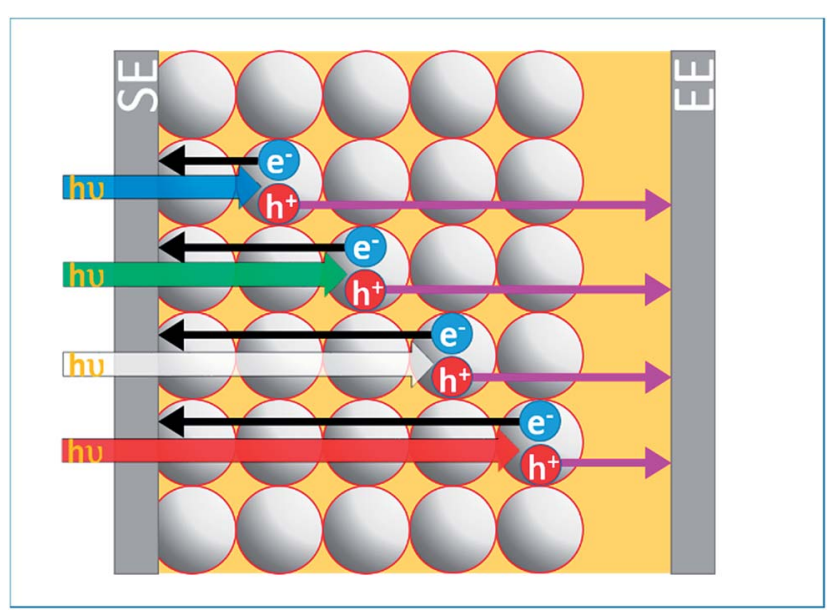

Fig. 3 Simplified schematic of a DSSC cross section. Coloured arrows illustrate various wavelengths and subsequent photogeneration of charge carriers. Black and purple arrows illustrate the average diffusion distance for electrons and holes, respectively. 
lower current when compared to SE-illumination, at lower light intensities, primarily due to the reduced optical transmittance of TEC8 glass relative to TEC15 glass. Nevertheless, it is later shown that the photocurrent is substantially higher for EEillumination at high light intensities, where mass transport limitations may occur. Finally, the use of higher than one sun intensities and non-uniform absorption can be compared to other DSSCs with more strongly absorbing sensitisers, in terms of equivalent photocurrent density. Also, higher than one sun light intensities can be used to more easily distinguish differences in limiting current and operating limitations.

\subsection{Photocurrent linearity and photocurrent turn-on transients}

Deviations in the linearity of photocurrent as a function of light intensity can be used to determine the presence of current limitations. ${ }^{15,16,47,48}$ Fig. $4 \mathrm{a}$ and $\mathrm{b}$ compare the steady state current $\left(J_{\mathrm{ss}}\right)$ obtained after equilibrating for 5 seconds under constant illumination, for different illumination wavelengths and illumination directions. The effects of the photoanode thickness and non-uniform absorption profile are compared. Most notably, Fig. 4a and b show that stronger EE-absorption (i.e., EE-blue) results in significantly higher and more linear $J_{\text {Ss }}$, irrespective of increasing photoanode thickness or light intensity. Conversely, stronger SE-absorption (i.e., SE-blue) results in lower $J_{\mathrm{Ss}}$, which scales linearly until $\sim 0.5$ sun (see the vertical dashed line). Above 0.5 sun, $J_{\text {Ss }}$ sharply decreases and then scales linearly with a reduced slope, which shows that current becomes limited with respect to light intensity. This indicates that recombination sharply increases and subsequently scales proportionally with light intensity. Comparing at 2 suns, $J_{\mathrm{SS}}$ increases in the order of SE-blue, SEgreen, SE-white, SE-red, EE-red, EE-white, EE-green and EEblue. Overall, at higher intensities, $J_{\mathrm{Ss}}$ increases as the absorption profile is skewed to the EE-side, and absorption is minimised from the SE-side. This is consistent with current limitations resulting from the insufficient mass transport of $\left[\mathrm{Co}(\text { bipy })_{3}\right]^{3+}$ to the counter electrode. Moreover, this shows that current limitations significantly worsen when the $\left[\mathrm{Co}(\text { bipy })_{3}\right]^{3+}$ diffusion distance through the $\mathrm{TiO}_{2}$ mesopores increases. This is in agreement with rotating disc electrode voltammetry measurements of redox mediator diffusion through $\mathrm{TiO}_{2}$ films. ${ }^{14}$ Importantly, this shows that the spatial absorption profile across the photoanode significantly contributes to current limitations, and even more so than parameters such as photoanode thickness and light intensity. Finally, Fig. 4a and b show that $J_{\mathrm{Ss}}$ tends to scale more invariantly with respect to the wavelength (see black arrows), for thinner photoanodes under SE-illumination and thicker photoanodes under EEillumination. These trends indicate two different underlying current limiting processes, which are examined below.

Photocurrent turn-on transients can be used to identify current limiting processes in the time domain. Fig. 4c-f show the photocurrent transient response, following illumination from dark, under short-circuit conditions. For brevity, only 1 sun photocurrent transients are compared here. Comparing SEillumination, Fig. 4c and d show that strong SE-absorption results in an initial peak $\left(J_{\text {peak }}\right)$, followed by a secondary $J_{\text {peak }}$ decay transient, reaching $J_{\mathrm{Ss}}$ after $10^{-2}-1$ s. Unlike $J_{\mathrm{Ss}}, J_{\text {peak }}$ scales linearly with light intensity and represents the maximum extractable current prior to current limitations. Fig. 4c and
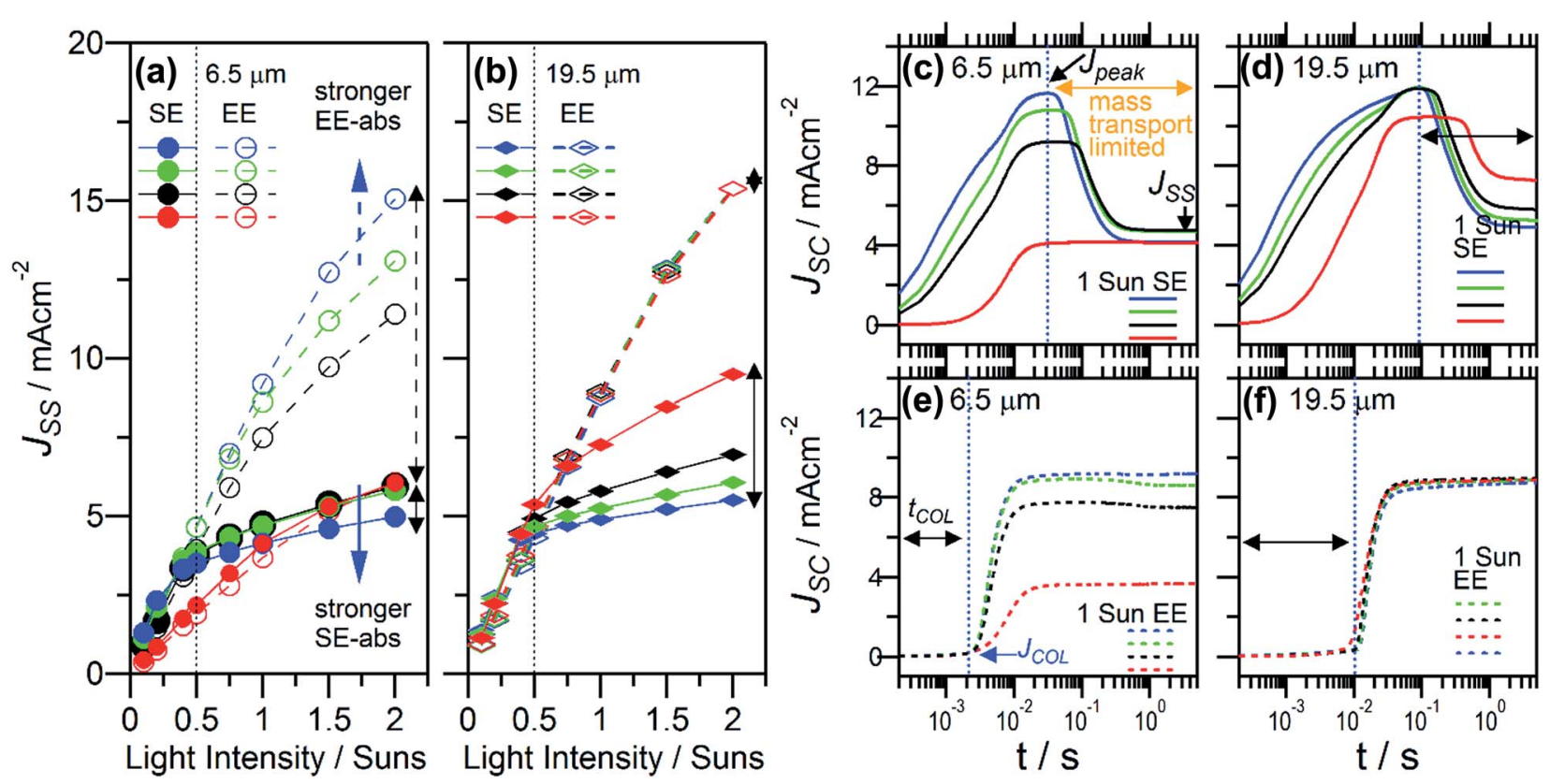

Fig. 4 ( $a$ and b) Steady-state short-circuit photocurrent $\left(J_{S S}\right)$ versus light intensity. Comparison of SE/EE-illumination (solid/open markers). (c-f) Short-circuit photocurrent turn-on transients, following dark to 1 sun illumination. Comparison of SE-illumination (top) and EE-illumination (bottom). Comparison of photoanode thicknesses and illumination wavelengths (blue, green, white and red illumination). Additional cells with $>6.5 \%$ PCE and different $\mathrm{TiO}_{2}$ films shown in Fig. S9 and 10† have identical trends. 
d show that $J_{\text {peak }}$ increases proportionally with more strongly absorbed wavelengths, although this reaches a plateau as $\mathrm{TiO}_{2}$ film thickness increases. This shows that the devices are limited by electron injection from the dye and/or electron collection through the $\mathrm{TiO}_{2}$ film. The timescale of the subsequent $J_{\text {peak }}$ decay transients is consistent with redox mediator diffusion and has been experimentally attributed to the mass transport limitations of the redox mediator..$^{\mathbf{8} 14,18,19}$ Mass-transport limitations typically arise due to the depletion of oxidised redox mediators at the counter electrode.$^{48}$ For cobalt-based DSSCs, the oxidised $\left[\mathrm{Co}(\mathrm{bipy})_{3}\right]^{3+}$ mediator is usually the mass transport limiting species. The mass transport limitations of the reduced $\left[\mathrm{Co}(\text { bipy })_{3}\right]^{2+}$ mediator can be disregarded given the similar diffusion coefficients of $\left[\mathrm{Co}(\mathrm{bipy})_{3}\right]^{2+}$ and $\left[\mathrm{Co}(\mathrm{bipy})_{3}\right]^{3+}$ in acetonitrile, ${ }^{8,49}$ the significantly larger concentration of $\left[\mathrm{Co}(\text { bipy })_{3}\right]^{2+}$ in typical electrolytes, and the high dye regeneration efficiency of LEG4/cobalt DSSCs. ${ }^{50}$ The assertion that insufficient $\left[\mathrm{Co}(\text { bipy })_{3}\right]^{3+}$ mass transport leads to insufficient dye regeneration and increased electron-dye recombination ${ }^{18}$ is erroneous unless it somehow influences the diffusion of $\left[\mathrm{Co}(\text { bipy })_{3}\right]^{2+}$. Following the depletion of $\left[\mathrm{Co}(\text { bipy })_{3}\right]^{3+}$ at the counter electrode, electrons inside the $\mathrm{TiO}_{2}$ are prevented from flowing to the external circuit, due to charge conservation. This leads to increased electron-back recombination, which can occur either via $\left[\mathrm{Co}(\text { bipy })_{3}\right]^{3+}$ or the oxidised dye. Later on, this is shown to occur primarily at the FTO collecting contact of the working electrode. Comparing EE-illumination, Fig. 4e and $\mathrm{f}$ show that the photocurrent stabilises after $\sim 10^{-2}$ s of illumination, indicating the absence of $\left[\mathrm{Co}(\mathrm{bipy})_{3}\right]^{3+}$ mass transport limitations. This is consistent with the increased photogeneration of $\left[\mathrm{Co}(\mathrm{bipy})_{3}\right]^{3+}$ closer to the counter electrode, increasing the overall diffusion flux of $\left[\mathrm{Co}(\mathrm{bipy})_{3}\right]^{3+}$ to the counter electrode.

Interestingly, Fig. $4 \mathrm{e}$ and $\mathrm{f}$ show that under strong EEabsorption, the initial photocurrent rise transient is biphasic, comprising two independent single exponential rises. This consists of a slow rise shoulder preceding a fast rise, which follows a sharp transition occurring between $10^{-3}$ and $10^{-2} \mathrm{~s}$ (see the vertical dashed line, Fig. $4 \mathrm{e}$ and f). This shows that the overall collection of electrons in the external circuit is initially limited on the $10^{-4}-10^{-2} \mathrm{~s}$ time-scale. A similar rise shoulder has been previously reported in the literature for iodide-based DSSCs ${ }^{51}$ although the rise delay appears on the $10^{-4}-10^{-3} \mathrm{~s}$ timescale and is far less pronounced than that of Fig. 4 . The delay in current rise can be explained by the time taken for a sufficient number of electrons, injected from the EE-side, to diffuse through the $\mathrm{TiO}_{2}$ film and fill the electron trap states closer to the $\mathrm{TiO}_{2} /$ FTO interface. Overall, this process limits the initial electron collection in the external circuit and is thus referred to as " $t_{\mathrm{COL}}$ ". Moreover, $t_{\mathrm{COL}}$ linearly correlates with the electron transport time constant $\left(t_{\mathrm{tr}}\right)$, obtained in the subsequent measurements (ESI, Fig. S2 $\dagger$ ). Also, $t_{\mathrm{COL}}$ increases surprisingly linearly with photoanode thickness and decreases with light intensity, which is in agreement with previous observations for $t_{\mathrm{tr}}{ }^{52}$ In addition, $t_{\mathrm{COL}}$ exhibits a power law dependence on light intensity (ESI, Fig. S3†), as similarly reported for $t_{\mathrm{tr}}{ }^{53-56}$ These correlations may suggest that $t_{\mathrm{COL}}$ is equivalent to $t_{\mathrm{tr}}$, since both describe electron collection through the $\mathrm{TiO}_{2}$ film. Finally, it is interesting to note that the current reached at $t_{\mathrm{COL}}$, hereon referred to as " $\mathrm{COL}_{\mathrm{COL}}$ ", linearly correlates with $J_{\text {SS }}$ (ESI, Fig. S4 $\dagger$ ). This suggests that $J_{\text {ss }}$ may be determined from the initial rise shoulder of the turn-on photocurrent rise transient.

Fig. 5 shows the $J-V$ of an atypical DSSC with an extremely thick $\mathrm{TiO}_{2}$ film of $19.5 \mu \mathrm{m}$. This was intentionally used to study the effect of mass transport on the $J-V$ characteristics. Identical trends were reproduced with thinner $\mathrm{TiO}_{2}$ performance optimised DSSCs (see ESI Fig. S12 and 13†). Counterintuitively, the performance of DSSCs with mass transport limitations can be substantially improved with EE-illumination, strongly absorbing sensitisers and thicker photoanodes. This shows that thicker films are not inherently worse for mass transport rather that the real issue is the average distance that redox mediators need to travel through the film. Fig. 5 shows that stronger EE-absorption also leads to significantly greater PCE. At higher intensities, both $J_{\mathrm{SC}}$ and $V_{\mathrm{OC}}$ increase under stronger EE-absorption, which is consistent with the increased diffusion flux of $\left[\mathrm{Co}(\mathrm{bipy})_{3}\right]^{3+}$ to the counter electrode and reduced electron back recombination to $\left[\mathrm{Co}(\mathrm{bipy})_{3}\right]^{3+}$. Previous studies of iodide-based DSSCs have reported lower PCE under EEillumination (relative to SE-illumination). ${ }^{38}$ Typically, this can be attributed to light absorption losses to the bulk electrolyte, since EE-illumination increases the distance that light travels through the bulk electrolyte prior to reaching the sensitised photoanode. In contrast, cobalt bipyridine-based electrolytes are significantly less absorbing and can be more suitable for operation under EE-illumination. Also, due to the presence of the $J_{\text {peak }}$ decay transients (as observed in Fig. $4 \mathrm{c}$ and d), the cells

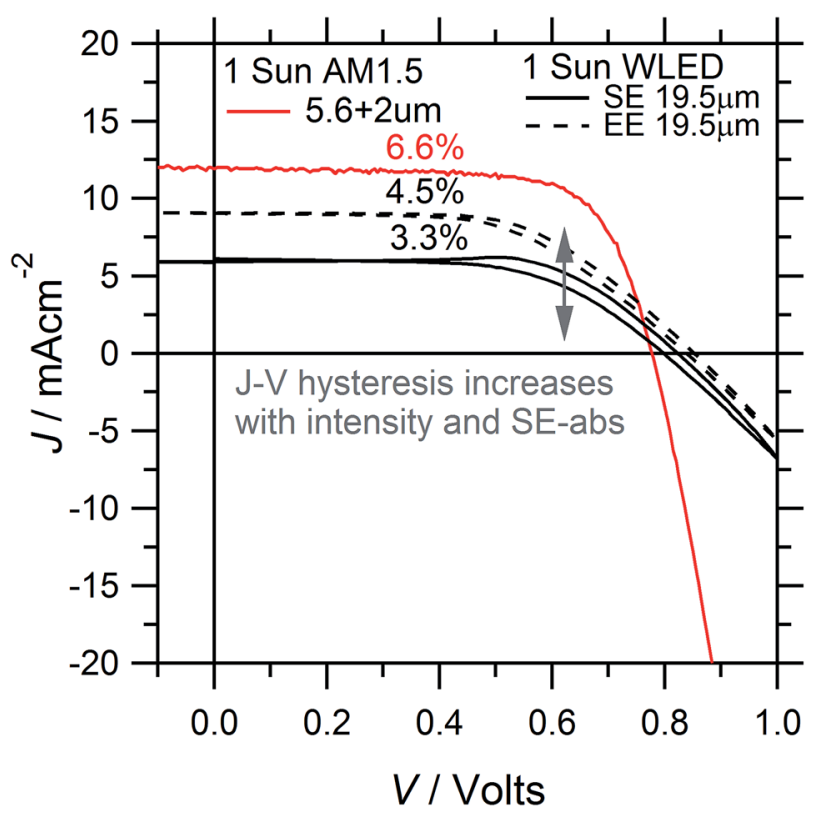

Fig. $5 \mathrm{~J}-V$ comparing an atypical $19.5 \mu \mathrm{m}$ device (WLED) and efficiency optimised device (AM 1.5), with PCE overlaid. Hysteresis increases for strong SE-illumination and thick films. See ESI Fig. S12 $\uparrow$ for 1 sun AM $1.5 \mathrm{~J}-V \mathrm{~s}$ of other efficiency optimised DSSCs. 
were initially equilibrated under short-circuit conditions and illumination, prior to scanning the $J-V \mathrm{~s}$. This prevents the overestimation of $J_{\mathrm{SC}}$ and is generally recommended for the measurement of cells which do not quickly stabilise to $J_{\mathrm{ss}}$. To compare hysteresis, the $J-V \mathrm{~s}$ were scanned cyclically, from $0 \mathrm{~V}$ to $1 \mathrm{~V}$ to $-0.1 \mathrm{~V}$ and return. Fig. 5 shows that hysteresis increases, especially near the maximum power point, when scanning in the direction from $V_{\mathrm{OC}}$ to $J_{\mathrm{SC}}$, under strong SE-absorption and higher light intensities. This leads to an overshoot in current, leading to an overestimated fill-factor and PCE. Such overshoots are not present under EE-illumination. The trends of $J-V$ overshoot hysteresis were also observed for efficiency optimised DSSCs at higher light intensities (ESI Fig. S13†). While this issue is less pertinent for optimised ACN devices at 1 sun, it can be highly noticeable for DSSCs with more viscous electrolytes. Similar overshoots can be observed in $J-V$ s reported in the literature, ${ }^{19,57}$ including some that have not been commented upon..$^{34,35,58}$ The effect of applied bias on the $J-V$ hysteresis will be reported elsewhere..$^{59}$

Additionally, devices with performance optimised $\mathrm{TiO}_{2}$ films were characterised under AM 1.5 solar irradiance (see ESI, Fig. S12†). A slight improvement in photocurrent was obtained when changing from DSL18NRT-based $\mathrm{TiO}_{2}$ films to bilayer $\mathrm{TiO}_{2}$ films consisting of DSL30NRD and WER2-O scattering particles. It should be noted that the $\mathrm{TiO}_{2}$ porosity is greater for films made with DSL30NRD, when compared to DSL18NRT. In addition, lower concentrations of $\mathrm{TiCl}_{4}$ post treatment were tested for the DSL30NRD-based DSSCs. Measured under AM 1.5, the improvement in 1 sun $J-V$ performance was negligible for the different $\mathrm{TiO}_{2}$ films. Overall, the 1 sun efficiencies were similar (Fig. S12 $\dagger$ ) showing that the devices are mainly limited by light absorption and the diffusion distance through the $\mathrm{TiO}_{2}$ film, as opposed to the porosity of the $\mathrm{TiO}_{2}$ film. In later sections, photocurrent transient measurements were repeated with these higher efficiency devices and similar trends could be observed.

\subsection{Short-circuit charge extraction current decay transients}

Charge extraction can be used to estimate the density of excess charge carriers stored inside the $\mathrm{TiO}_{2}$ photoanode $\left(Q_{\mathrm{SC}}\right)$, under illumination and at short-circuit. However, this requires minimal recombination losses in order to fully extract the excess charge. ${ }^{43,44,60}$ Albeit unconventional, charge extraction can also be ideal for analysing collection kinetics. Under dark and short-circuit conditions, the excess charge relaxes predominantly via collection and recombination. Typically, the $Q_{\mathrm{SC}}$ versus $J_{\mathrm{SS}}$ curve follows a power law, ${ }^{43,61}$ assuming that collection dominates, which appears linear on a log-log plot (hereon, power law trends are referred to as "linear"). However, sub-linear deviations can arise in the $Q_{\mathrm{SC}}$ curves when the collection efficiency changes as a function of light intensity. Previous work shows that non-linear $Q_{\mathrm{SC}}$ deviations can be caused by a reduction in the total concentration of $\left[\mathrm{Co}(\text { bipy })_{3}\right]^{3+}$ in the bulk electrolyte. ${ }^{15}$ By extension, the following results show that non-linear $Q_{\mathrm{SC}}$ deviations can also arise, for a fixed bulk electrolyte, purely as a function of the steady-state photogeneration profile.
Most strikingly, Fig. 6 shows that SE/EE-illumination directionality significantly affects the $Q_{\mathrm{SC}}$ curve linearity. To compare linearity, a power law extrapolation was applied to the linear regions of the $Q_{\mathrm{SC}}$ curves, which is shown for EE-blue (dashed blue line) and SE-blue (solid blue line). Under EE-illumination, the $Q_{\mathrm{SC}}$ curves (open markers) tend to be linear and overlap, irrespective of the light intensity, thickness or illumination wavelength; with the exception of red illumination for which $Q_{\text {SC }}$ is slightly lower. This shows that under EE-illumination, the steady-state electron generation profile scales invariantly, with respect to the thickness and wavelength, whilst collection efficiency remains constant. In stark contrast, SE-illumination leads to the $Q_{\mathrm{SC}}$ curves (solid markers) deviating from linearity above $\sim 0.5$ sun $\left(\sim 3-4 \mathrm{~mA} \mathrm{~cm}{ }^{-2}\right.$, vertical blue dashed line), especially at higher light intensities (blue arrows). Moreover, the magnitude and shape of the $Q_{\mathrm{SC}}$ curves are affected by both the thickness and the wavelength. Fig. 6a-d show that $Q_{\mathrm{SC}}$ shifts vertically down for stronger SE-absorption and thicker films. This is most visible when comparing SE-blue (see black arrows). Such downward shifts in $Q_{\mathrm{SC}}$ can indicate a shift in the conduction band edge potential or faster recombination kinetics at the $\mathrm{TiO}_{2} /$ electrolyte interface. ${ }^{62}$ The former is less likely, given that an identical cell under EE-illumination results in $Q_{\mathrm{SC}}$ scaling invariantly, ruling out the possibility of electrolytic components significantly influencing the $\mathrm{TiO}_{2}$ surface charges. Typically, $Q_{\mathrm{SC}}$ would be expected to increase for thicker films, given the increased capacity of the photoanode to generate and store charge. However, thicker films and stronger SE-absorption contribute to the increased accumulation of $\left[\mathrm{Co}(\text { bipy })_{3}\right]^{3+}$ inside the mesoporous $\mathrm{TiO}_{2}$ film, which increases electron recombination to $\left[\mathrm{Co}(\text { bipy })_{3}\right]^{3+}$. Up to $\sim 0.5$ sun, the $Q_{\mathrm{SC}}$ curves remain linear as recombination scales proportionally with light intensity. The vertical down shifts in $Q_{\mathrm{SC}}$ correspond to increased recombination losses, which scale proportionally with light intensity. However, at higher intensities, recombination scales non-linearly which results in the $Q_{\mathrm{SC}}$ deviating from linearity. Moreover, at higher light intensities, the $Q_{\mathrm{SC}}$ curve gradually changes in shape as a function of SE-absorption and thickness. This is most visible when comparing SE-blue at higher light intensities (vertical dashed blue line); sub-linear deviations at higher intensities are highlighted (blue arrows). For instance, Fig. 6a-c show that thinner cells exhibit $Q_{\mathrm{SC}}$ deviations which decrease below linearity, whereas Fig. 6d shows that thicker cells exhibit $Q_{\mathrm{SC}}$ deviating above linearity. At first glance, these trends appear to violate charge conservation; however, the former indicates excessive recombination losses, whereas the latter indicates reducing recombination losses. Compared to Fig. 4, this shows that the $Q_{\mathrm{SC}}$ deviations only occur when there is a current limitation. To further analyse how current limitation affects the overall collection kinetics, the raw current decay transients obtained from charge extraction measurements were analysed.

Charge extraction photocurrent decay transients show the overall current collected to the external circuit, as a function of time. Under illumination and short-circuit conditions, the steady-state electron concentration profile follows an exponential distribution, as a function of light intensity. ${ }^{51,63}$ The 


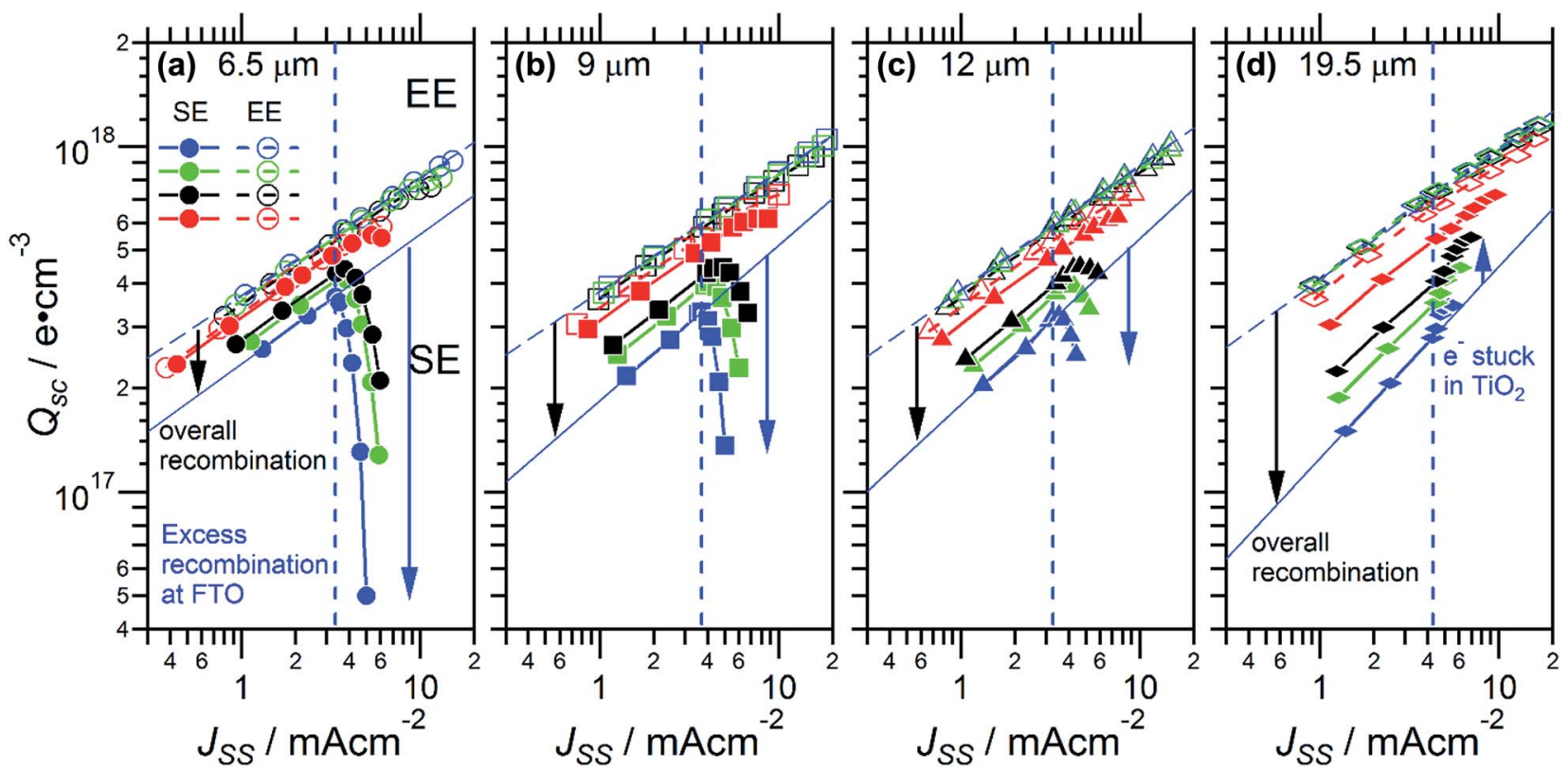

Fig. 6 Excess charge density extracted from short-circuit $\left(Q_{S C}\right)$. (a-d) Increasing photoanode thickness (6.5-19.5 $\left.\mu \mathrm{m}\right)$. Comparison of SE/EEillumination directions (solid/open markers). Comparison of illumination wavelengths.

subsequent current decay transient in the dark depends on a number of dynamically changing factors including the total electron concentration, the spatial electron concentration gradient, electron trapping and the electrolyte concentration profile. The interpretation of such transients is complicated and to the best of our knowledge has yet to be attempted. Fig. 7a shows the typical photocurrent decay transient, similarly observed in the literature, ${ }^{\mathbf{4 3 , 6 4 , 6 5}}$ which can be described as comprising an initial shoulder followed by an exponential tail. Time domain analysis can be simplified by qualitatively analysing the photocurrent transients as a function of the photogeneration profile. In principle, assuming that excess recombination to $\left[\mathrm{Co}(\text { bipy })_{3}\right]^{3+}$ is occurring, there should be significantly increased current decay on the $10^{-3} \mathrm{~s}$ timescale, as

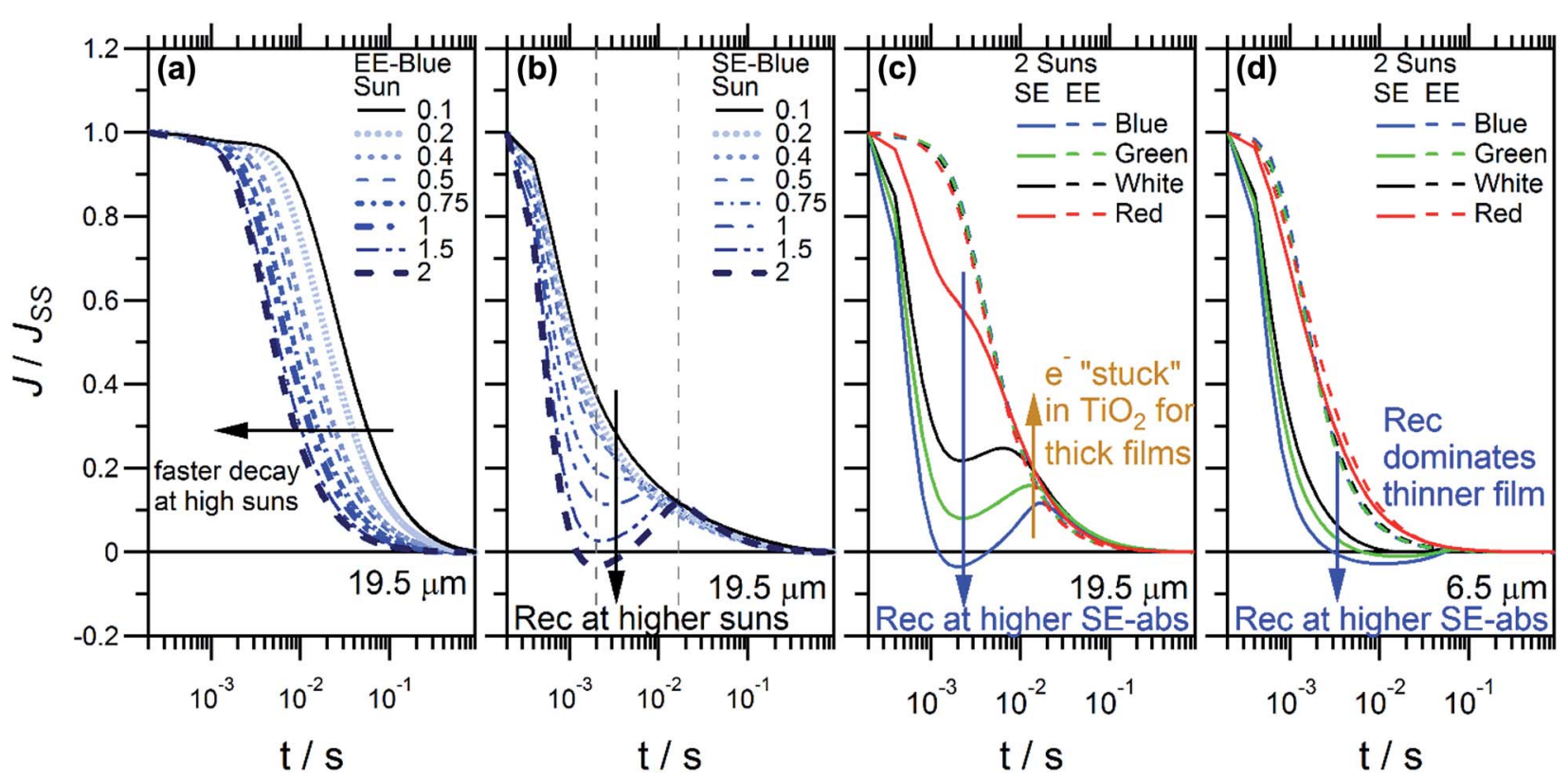

Fig.7 Normalised $Q_{S C}$ photocurrent decay transients in the dark. (a) Comparison of light intensity (0.1-2 suns) for the $19.5 \mu \mathrm{m}$ cell under SE-blue illumination. (b) Comparison of light intensity (0.1-2 suns) for the $19.5 \mu \mathrm{m}$ cell under SE-blue illumination. (c) Comparison of illumination wavelengths and SE/EE directionality at 2 suns for the $19.5 \mu \mathrm{m}$ cell. (d) Comparison of illumination wavelengths and SE/EE directionality at 2 suns for the $6.5 \mu \mathrm{m}$ cell. ESI Fig. S11† shows that trends also apply to high efficiency cells. 
previously observed in the turn-on photocurrent transients (Fig. 4c and d). Most notably, Fig. 7b-d show a greater current decay rate on the $10^{-3}-10^{-2} \mathrm{~s}$ timescale, which increases with light intensity and stronger SE-absorption. No such peaks are observed under EE-illumination. Again, this increased rate of current decay in Fig. 7b-d is consistent with greater photogeneration of $\left[\mathrm{Co}(\text { bipy })_{3}\right]^{3+}$ inside the mesopores. Also, this shows that significant quantities of $\left[\mathrm{Co}(\text { bipy })_{3}\right]^{3+}$ remain inside the mesoporous $\mathrm{TiO}_{2}$, following switching to the dark. This temporarily increases electron back recombination, which decreases as $\left[\mathrm{Co}(\text { bipy })_{3}\right]^{3+}$ gradually diffuses out of the pores. The decay rate increases since recombination provides an additional pathway for the excess electrons to relax. As such, the initial current decay rate on the $10^{-4}-10^{-3} \mathrm{~s}$ timescale is also faster under higher intensities and stronger SE-absorption. Moreover, Fig. 7b and c show that following the excess recombination dip, the current transient temporarily rises again. This shows that excess electrons remained inside the $\mathrm{TiO}_{2}$ and could not be fully extracted until the rate of electron recombination to $\left[\mathrm{Co}(\text { bipy })_{3}\right]^{3+}$ had decreased. Also, this indicates that the thicker photoanodes actually store more electrons, however, extract less charge due to greater recombination. This accounts for the upwards curve of $Q_{\mathrm{SC}}$ observed in Fig. 7d; despite greater overall net recombination losses, more electrons gradually accumulate inside the $\mathrm{TiO}_{2}$ at higher intensities. In addition, when the current transient reaches temporarily zero in Fig. $7 \mathrm{~b}-\mathrm{d}$, the rates of recombination to $\left[\mathrm{Co}(\text { bipy })_{3}\right]^{3+}$ and electron collection are momentarily equal. Also, under high intensities and strong SE-absorption, the electron flow can even reverse its direction. The reversal in current can only occur when electrons are flowing back from the external circuit and into the photoanode, when the net recombination flux exceeds the collection flux. Given that there is already an excess number of electrons inside the $\mathrm{TiO}_{2}$, it is unlikely that recombination via the mesoporous $\mathrm{TiO}_{2}$ can account for net current reversal. As such, this indicates that significant quantities of $\left[\mathrm{Co}(\text { bipy })_{3}\right]^{3+}$ accumulate inside the mesoporous $\mathrm{TiO}_{2}$ and at the FTO interface, resulting in both recombination with electrons in $\mathrm{TiO}_{2}$ and electrons from the external circuit. To confirm that recombination occurs primarily at the FTO interface, follow-up measurements were made on similar cells comparing the effect of $\mathrm{TiO}_{2}$ blocking layers on the FTO.

Fig. 8 compares the charge extraction current decay transients, for comparable $6.5 \mu \mathrm{m}$ cells, albeit prepared with different $\mathrm{TiO}_{2}$ blocking layers on FTO. The blocking layer on FTO adds a compact layer of $\mathrm{TiO}_{2}$ which suppresses backrecombination of electrons via the FTO collecting contact with $\left[\mathrm{Co}(\text { bipy })_{3}\right]^{3+}$. Thus far, all devices were prepared using a $\mathrm{TiCl}_{4}$ treatment, which introduces a thin compact $\mathrm{TiO}_{2}$ blocking layer onto the FTO interface. The blocking effect increases in the ascending order of untreated $\mathrm{FTO}, \mathrm{TiCl}_{4}$ treated FTO and compact $\mathrm{TiO}_{2}$ treated FTO prepared with spray pyrolysis. Fig. 8 shows that reduced FTO blocking leads to faster current decay with an increased dip at $2 \mathrm{~ms}$, which indicates faster recombination. For the thickest blocking layer, significantly more charge is extracted with a longer current decay shoulder, and recombination on the $10^{-3} \mathrm{~s}$ timescale is greatly reduced.

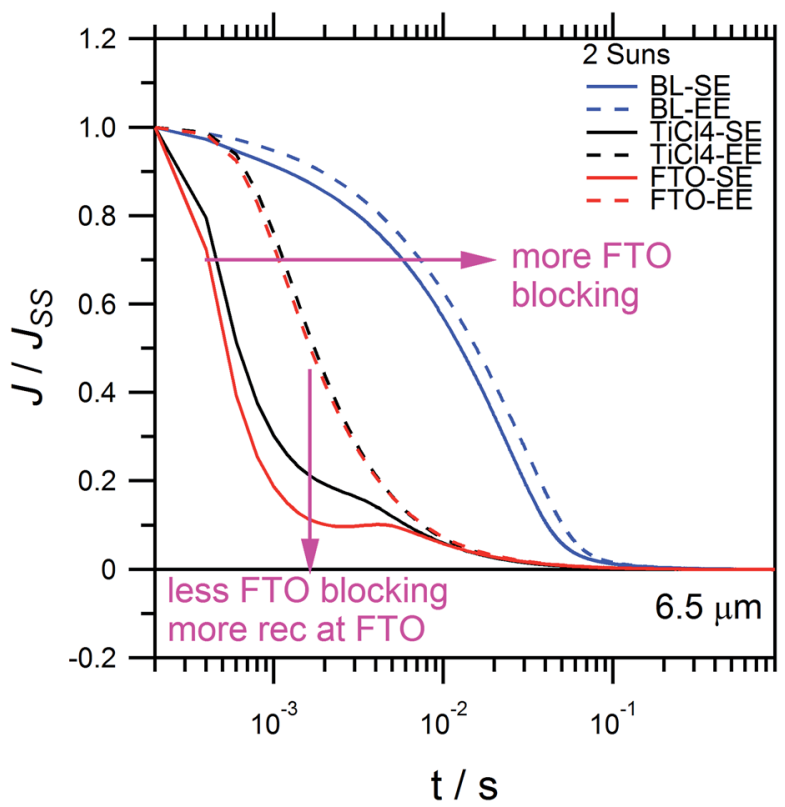

Fig. 8 Comparison of charge extraction current decay transients for additional $6.5 \mu \mathrm{m}$ cells prepared with various FTO-blocking layers: compact $\mathrm{TiO}_{2}$ blocking layer $(\mathrm{BL}), \mathrm{TiCl}_{4}$ pre-treatment $\left(\mathrm{TiCl}_{4}\right)$ and untreated FTO (FTO). Comparison for 2 suns SE-blue and EE-blue illumination.

Similar to Fig. 6d, cells with blocking layers exhibit $Q_{\mathrm{SC}, \mathrm{SE}}$ deviations which rise (ESI, Fig. S3†). This shows that when FTO recombination is suppressed, there is a net build-up of electrons inside the $\mathrm{TiO}_{2}$, due to $\left[\mathrm{Co}(\text { bipy })_{3}\right]^{3+}$ depletion at the counter electrode. Overall, Fig. 8 shows that recombination occurs primarily at the FTO contact, as opposed to the mesoporous $\mathrm{TiO}_{2}$ film. This shows that sensitisers with steric alkoxy chains, such as LEG4, are quite effective in suppressing the recombination of electrons in the mesoporous $\mathrm{TiO}_{2}$ with $\left[\mathrm{Co}(\text { bipy })_{3}\right]^{3+}$. Moreover, strong EE-absorption can also be effective in suppressing FTO recombination, as shown by FTOEE in Fig. 8. This shows that FTO blocking layers are not inherently necessary for EE-illuminated cells. Finally, similar to Fig. 6d, the $Q_{\mathrm{SC}}$ curves of the devices with thicker $\mathrm{TiO}_{2}$ blocking layers on the FTO (ESI, Fig. S5 $\dagger$ ) tend to deviate above linearity. This shows that when electron recombination at the FTO substrate is suppressed, and the device is limited by $\left[\mathrm{Co}(\text { bipy })_{3}\right]^{3+}$ mass transport, and then more electrons can accumulate inside the $\mathrm{TiO}_{2}$ film, as a function of current density. In addition, this non-linear recombination process has been recently confirmed with $8.2 \%$ copper polypyridine redox mediator-based DSSCs. ${ }^{66}$

\subsection{Small perturbation photocurrent decay transients}

Finally, small perturbation photocurrent transients will be compared with large perturbation photocurrent transients, to determine whether similar information can be obtained under steady-state illumination. Typically, small perturbation transients at steady-state are more frequently used in the litera-

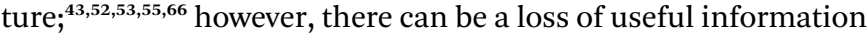


when linearizing the photocurrent response. ${ }^{\mathbf{4 4 , 6 0}}$ Suggestions for more accurate measurements of electron transport are discussed below.

Fig. 9 shows the photocurrent response, following a small square-wave optical modulation in light intensity, under steadystate short-circuit conditions. Small perturbation photocurrent decay transients are commonly used to calculate the electron transport time-constant $\left(\tau_{\mathrm{tr}}\right)$, which describes the average time required for the photoinjected electron to diffuse through the mesoporous $\mathrm{TiO}_{2}$ to the external circuit. This can be determined from a single exponential decay fit to the small perturbation photocurrent decay transient. ${ }^{\mathbf{4 3 , 5 2 , 5 3}}$ Typically, DSSCs with high collection efficiency are expected to exhibit a mono-exponential decay, which can be observed in Fig. 10 for devices with stronger EE-absorption and thicker $\mathrm{TiO}_{2}$ films. Interestingly, the decay time-constants obtained under EE-illumination appear to be invariant with respect to the illumination wavelength (ESI, Fig. S6†). This shows that electron transport measurements under EE-illumination are less sensitive to the colour spectrum of the light source, which could also improve the comparability of electron transport measurements between different labs. This is in agreement with previous studies which have also recommended EE-illumination for more reliable measurement of electron transport. ${ }^{37,39}$

Similar to Fig. 7, the photocurrent decay transients in Fig. 10 show that excess electron recombination to $\left[\mathrm{Co}(\text { bipy })_{3}\right]^{3+}$ occurs on the $10^{-3}-10^{-2} \mathrm{~s}$ timescale, which increases for stronger SEabsorption, higher light intensities and thinner $\mathrm{TiO}_{2}$ films. In addition, the small perturbation rise and decay transients in Fig. 9 (see dashed lines) are essentially identical, unlike the respective large perturbation transients in Fig. 4 and 7. Similar

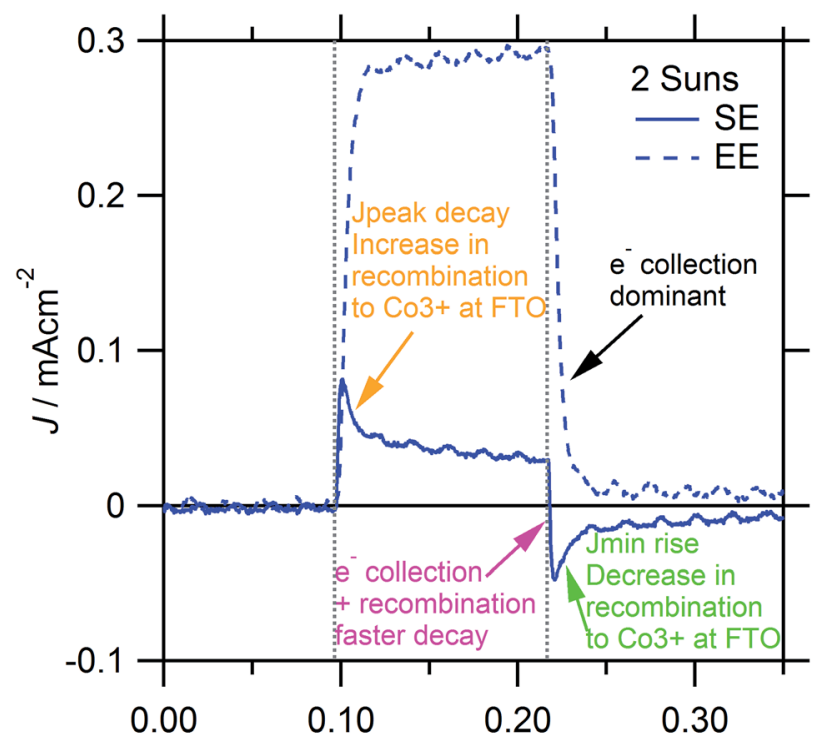

$\mathrm{t} / \mathrm{s}$

Fig. 9 Short-circuit photocurrent response, following a small optical perturbation under short-circuit illumination conditions. Comparison of SE/EE-illumination directionality for SE-blue illumination at 2 suns. Baseline subtracted by $J_{\text {SS }}$.
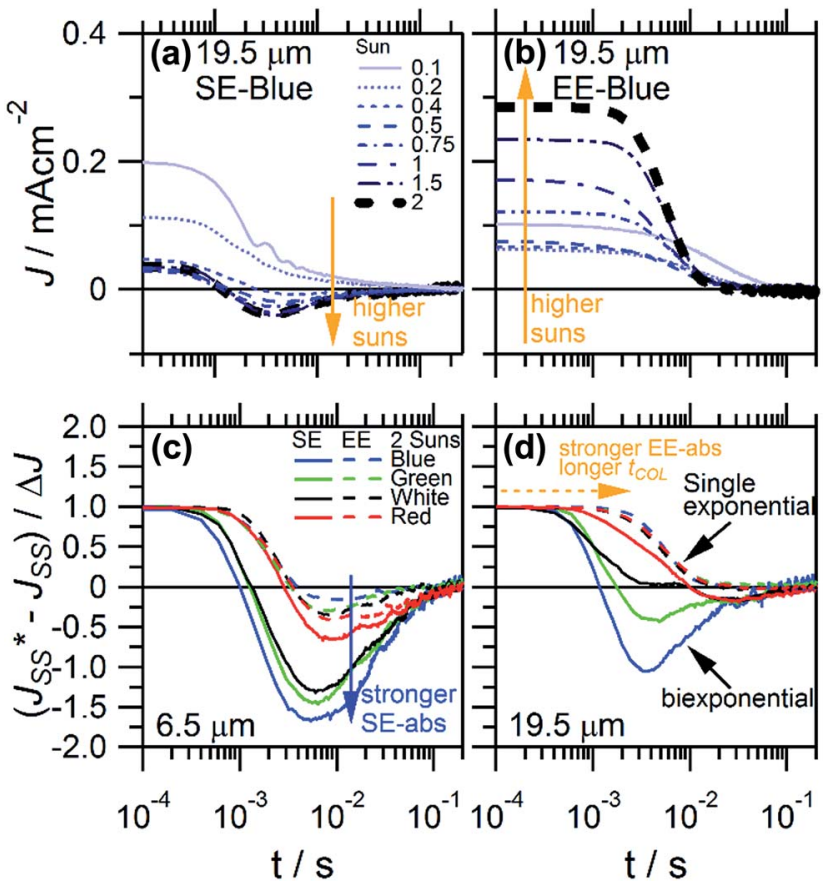

Fig. 10 Photocurrent decay transients following small optical perturbation, measured under steady-state illumination and shortcircuit conditions. Baseline subtracted by steady state current $\left(J_{S S}\right)$ and normalised at the start of the current decay. (a and b) Comparison of increasing light intensity (0.1-2 suns). (c and d) Comparison of illumination wavelengths.

to Fig. 4, Fig. 9 shows that $J_{\text {peak }}$ decay and $J_{\text {min }}$ rise transients also occur on the $10^{-2}-1 \mathrm{~s}$ timescale, which corresponds to the gradual increase or decrease in electron recombination to $\left[\mathrm{Co}(\text { bipy })_{3}\right]^{3+}$ at the FTO interface, respectively (see Fig. 9, orange and green arrows). Furthermore, Fig. 9 (see the purple arrow) and Fig. 10 show that, under $\left[\mathrm{Co}(\text { bipy })_{3}\right]^{3+}$ mass transport limitation, the photocurrent decay transient is faster. This sharply reduces the decay time constant (ESI, Fig. S6†), which subsequently describes electron recombination, in addition to electron collection. When excess recombination occurs, the overall photocurrent decay transient fits well to a biexponential function, although the reason for this is not entirely clear. Such an interpretation would only be valid assuming that there are two independent processes by which the excess charge can relax. However, it may not be expected for electron collection and recombination to occur independently, given that both processes could affect the overall concentration of excess electrons inside the $\mathrm{TiO}_{2}$ film. Otherwise, this could be interpreted as the relaxation of $\left[\mathrm{Co}(\text { bipy })_{3}\right]^{3+}$ accumulated near the FTO interface contributing to net electron recombination, primarily via the electrons inside the FTO substrate, and independently of the electrons inside the mesoporous $\mathrm{TiO}_{2}$ film. This hypothesis is supported by a decrease in excess recombination, for devices with an increased thickness of pinhole $\mathrm{TiO}_{2}$ blocking layers on FTO (ESI, Fig. S7 $\dagger$ ). Finally, it is interesting to note that similar to Fig. 7, 10c and d show that the photocurrent decay transient is preceded by an initial slow decay shoulder, which increases 
with $\mathrm{TiO}_{2}$ film thickness and stronger EE-absorption. The initial delay could relate to $t_{\mathrm{COL}}$, which was observed in the turn-on rise photocurrent transients in Fig. 4, and would be consistent with the increased delay in collecting electrons which are photoinjected further from the collecting FTO contact. However, to further confirm this, additional measurements with higher resolution are required. All these trends have been reproduced in high efficiency DSSCs with various optimised $\mathrm{TiO}_{2}$ film structures (ESI, Fig. S13-15†).

Overall, small perturbation transients yield similar information to large perturbation transients. However, given the much smaller range of the data signal, the measurements of photocurrent can be highly sensitive to noise and drift - the latter of which can be improved through time-consuming averaging. In general, greater noise was observed at lower intensities whereas greater drift was observed at higher intensities. Whatever the case, devices more prone to drift will be less suitable for small perturbation measurements and may be better measured using large perturbation measurements. Importantly, the presence of current limitations such as $\left[\mathrm{Co}(\text { bipy })_{3}\right]^{3+}$ mass transport can be harder to distinguish from small perturbation transients, especially at lower light intensities. Therefore, it is highly recommended to measure large perturbation turn-on transients, prior to measuring small perturbation transients or any other steady-state measurements, in order to avoid inaccuracy in the determination of collection-dependent variables such as electron transport time and extracted charge density.

\section{Conclusions}

In summary, non-uniform intense absorption from the substrate-electrode side (strong SE-absorption) can significantly contribute to both the gradual depletion of $\left[\mathrm{Co}(\text { bipy })_{3}\right]^{3+}$ at the counter electrode and the increased accumulation of $\left[\mathrm{Co}(\text { bipy })_{3}\right]^{3+}$ inside the electrolyte-infiltrated $\mathrm{TiO}_{2}$ film. This greatly increases electron recombination to $\left[\mathrm{Co}(\text { bipy })_{3}\right]^{3+}$, especially at the FTO collecting contact of the working electrode. The recombination can be suppressed via the addition of pinholefree $\mathrm{TiO}_{2}$ blocking layers on the FTO or by increasing photogeneration from the EE-side, thereby reducing the amount of $\left[\mathrm{Co}(\text { bipy })_{3}\right]^{3+}$ close to the FTO interface. More importantly, stronger EE-absorption reduces the overall diffusion distance of $\left[\mathrm{Co}(\text { bipy })_{3}\right]^{3+}$ through the electrolyte-infiltrated $\mathrm{TiO}_{2}$ film. This substantially alleviates the mass transport limitations of $\left[\mathrm{Co}(\text { bipy })_{3}\right]^{3+}$ to the counter electrode.

More generally, we have developed a powerful method for the interpretation of both large and small photocurrent transients. Through the combination of the illumination wavelength and illumination direction, we directly control the subsequent photogeneration profile of charge carriers throughout the mesoporous $\mathrm{TiO}_{2}$ film. By analysing photocurrent transients in the time domain, the time-of-flight transits for electron and hole collection kinetics could be observed. Using this approach, we could directly simplify the interpretation of large perturbation phototransients directly in the time domain, using a qualitative analysis. Furthermore, the large perturbation phototransients yield similar if not more information than the standard small perturbation phototransients. The further use of large perturbation photocurrent transients is recommended because of their speed, simplicity and repeatability.

The findings of this work are especially relevant to the development of more stable DSSCs with viscous electrolytes, which are likely to be limited by the mass transport of the redox mediator. This work shows that the absorption profile can exacerbate mass transport issues in acetonitrile-based DSSCs however, this work is not intended for the optimisation of acetonitrile-based DSSCs. It is aimed at providing strategies to optimise the efficiency of DSSCs with more viscous electrolytes. This work should encourage further optimisation of alternative redox mediator DSSCs (such as cobalt polypyridine or copper polypyridine) using more robust viscous electrolytes and EEside optimisation. Additional work is required to optimise the addition of $\mathrm{TiO}_{2}$ scattering layers for EE-side absorption. The performance optimisation of more viscous electrolyte cobaltbased DSSCs in 3-methoxypropionitrile is being carried out in separate ongoing experiments, and preliminary results have yielded greater than $8 \%$ PCE at 1 sun. In such devices, it should be important to maximise light absorption from the EE-side or to minimise light absorption near the collecting FTO interface of the working electrode. Further improvements in performance can be possible, for instance, by reducing the concentration of the oxidised redox mediator (i.e., $\left[\mathrm{Co}(\mathrm{bipy})_{3}\right]^{3+}$ ) in the bulk electrolyte, optimising the $\mathrm{TiO}_{2}$ porosity, and the addition of back-scattering $\mathrm{TiO}_{2}$ layers (on the SE-side). Additional passivation of the $\mathrm{TiO}_{2}$ photoanode for instance via the addition of $\mathrm{Al}_{2} \mathrm{O}_{3}$ barrier layers can also be used to further reduce recombination losses. Also, this work reintroduces the feasibility of bulkier redox mediators, which were previously disregarded due to slow mass transport. Hopefully, this work should encourage additional work into higher viscosity electrolytes, in order to replace volatile acetonitrile-based electrolytes, which should be a critical step forward towards the development of commercially viable DSSCs.

\section{Conflicts of interest}

There are no conflicts to declare.

\section{Acknowledgements}

This work was funded by the Swedish Energy Agency, the Swedish Research Council and the ST and UP for Energy Program.

\section{Notes and references}

1 B. O'Regan and M. Grätzel, Nature, 1991, 353, 737-740.

2 A. Hagfeldt, G. Boschloo, L. Sun, L. Kloo and H. Pettersson, Chem. Rev., 2010, 110, 6595-6663.

3 A. Yella, H.-W. Lee, H. N. Tsao, C. Yi, A. K. Chandiran, M. K. Nazeeruddin, E. W.-G. Diau, C.-Y. Yeh, 
S. M. Zakeeruddin and M. Grätzel, Science, 2011, 334, 629634.

4 S. Mathew, A. Yella, P. Gao, R. Humphry-Baker, B. F. E. Curchod, N. Ashari-Astani, I. Tavernelli, U. Rothlisberger, M. K. Nazeeruddin and M. Grätzel, Nat. Chem., 2014, 6, 242-247.

5 K. Kakiage, Y. Aoyama, T. Yano, K. Oya, J. Fujisawa and M. Hanaya, Chem. Commun., 2015, 51, 15894-15897.

6 H. Nusbaumer, J. Moser, S. M. Zakeeruddin, M. K. Nazeeruddin and M. Grätzel, J. Phys. Chem. B, 2001, 105, 10461-10464.

7 H. Nusbaumer, S. M. Zakeeruddin, J.-E. Moser and M. Grätzel, Chem.-Eur. J., 2003, 9, 3756-3763.

8 S. M. Feldt, E. A. Gibson, E. Gabrielsson, L. Sun, G. Boschloo and A. Hagfeldt, J. Am. Chem. Soc., 2010, 132, 16714-16724.

9 S. M. Feldt, G. Wang, G. Boschloo and A. Hagfeldt, J. Phys. Chem. C, 2011, 115, 21500-21507.

10 J.-H. Yum, E. Baranoff, F. Kessler, T. Moehl, S. Ahmad, T. Bessho, A. Marchioro, E. Ghadiri, J.-E. Moser, C. Yi, M. K. Nazeeruddin and M. Grätzel, Nat. Commun., 2012, 3, 631.

11 T. Uchiyama, T. N. Murakami, N. Yoshii, Y. Uemura, N. Koumura, N. Masaki, M. Kimura and S. Mori, Chem. Lett., 2013, 42, 453-454.

12 S. A. Sapp, C. M. Elliott, C. Contado, S. Caramori and C. A. Bignozzi, J. Am. Chem. Soc., 2002, 124, 11215-11222.

13 K. Miettunen, S. Jouttijarvi, R. Jiang, T. Saukkonen, J. Romu, J. Halme and P. Lund, J. Electrochem. Soc., 2014, 161, H138H143.

14 J. J. Nelson, T. J. Amick and C. M. Elliott, J. Phys. Chem. C, 2008, 112, 18255-18263.

15 R. Jiang, A. Anderson, P. R. F. Barnes, L. Xiaoe, C. Law and B. C. O'Regan, J. Mater. Chem. A, 2014, 2, 4751-4757.

16 H. Ellis, R. Jiang, S. Ye, A. Hagfeldt and G. Boschloo, Phys. Chem. Chem. Phys., 2016, 18, 8419-8427.

17 S. Nakade, Y. Makimoto, W. Kubo, T. Kitamura, Y. Wada and S. Yanagida, J. Phys. Chem. B, 2005, 109, 3488-3493.

18 H. Kim, S. Ko, I. Jang and N. Park, Chem. Commun., 2011, 47, 12637.

19 H. N. Tsao, P. Comte, C. Yi and M. Grätzel, ChemPhysChem, 2012, 13, 2976-2981.

20 T. T. Trang Pham, T. M. Koh, K. Nonomura, Y. M. Lam, N. Mathews and S. Mhaisalkar, ChemPhysChem, 2014, 15, 1216-1221.

21 L.-P. Heiniger, F. Giordano, T. Moehl and M. Grätzel, Adv. Energy Mater., 2014, 4, 1400168.

22 W. Xiang, F. Huang, Y. Cheng, U. Bach and L. Spiccia, Energy Environ. Sci., 2013, 6, 121-127.

23 W. Xiang, W. Huang, U. Bach and L. Spiccia, Chem. Commun., 2013, 49, 8997.

24 Y. Hao, W. Yang, L. Zhang, R. Jiang, E. Mijangos, Y. Saygili, L. Hammarström, A. Hagfeldt and G. Boschloo, Nat. Commun., 2016, 7, 13934.

25 F. Bella, Electrochim. Acta, 2015, 175, 151-161.

26 F. Bella, J. R. Nair and C. Gerbaldi, RSC Adv., 2013, 3, 15993.

27 F. Bella, E. D. Ozzello, S. Bianco and R. Bongiovanni, Chem. Eng. J., 2013, 225, 873-879.
28 G. P. Salvador, D. Pugliese, F. Bella, A. Chiappone, A. Sacco, S. Bianco and M. Quaglio, Electrochim. Acta, 2014, 146, 4451.

29 F. Bella, A. Sacco, G. Massaglia, A. Chiodoni, C. F. Pirri and M. Quaglio, Nanoscale, 2015, 7, 12010-12017.

30 F. Bella, A. Lamberti, A. Sacco, S. Bianco, A. Chiodoni and R. Bongiovanni, J. Membr. Sci., 2014, 470, 125-131.

31 F. Bella and R. Bongiovanni, J. Photochem. Photobiol., C, 2013, 16, 1-21.

32 F. Bella, D. Pugliese, J. R. Nair, A. Sacco, S. Bianco, C. Gerbaldi, C. Barolo and R. Bongiovanni, Phys. Chem. Chem. Phys., 2013, 15, 3706.

33 P. Wang, S. M. Zakeeruddin, R. Humphry-Baker and M. Grätzel, Chem. Mater., 2004, 16, 2694-2696.

34 S. M. Zakeeruddin and M. Grätzel, Adv. Funct. Mater., 2009, 19, 2187-2202.

35 P. Wang, S. M. Zakeeruddin, J.-E. Moser, R. Humphry-Baker and M. Grätzel, J. Am. Chem. Soc., 2004, 126, 7164-7165.

36 M. Marszalek, F. D. Arendse, J.-D. Decoppet, S. S. Babkair, A. A. Ansari, S. S. Habib, M. Wang, S. M. Zakeeruddin and M. Grätzel, Adv. Energy Mater., 2014, 4, 1301235.

37 J. Halme, K. Miettunen and P. Lund, J. Phys. Chem. C, 2008, 112, 20491-20504.

38 P. R. F. Barnes and B. C. O'Regan, J. Phys. Chem. C, 2010, 114, 19134-19140.

39 P. R. F. Barnes, A. Y. Anderson, S. E. Koops, J. R. Durrant and B. C. O'Regan, J. Phys. Chem. C, 2009, 113, 1126-1136.

40 J. Halme, G. Boschloo, A. Hagfeldt and P. Lund, J. Phys. Chem. C, 2008, 112, 5623-5637.

41 M. Berginc, U. Opara Krašovec, M. Jankovec and M. Topič, Sol. Energy Mater. Sol. Cells, 2007, 91, 821-828.

42 M. Berginc, U. Opara Krašovec, M. Hočevar and M. Topič, Thin Solid Films, 2008, 516, 7155-7159.

43 P. R. F. Barnes, K. Miettunen, X. Li, A. Y. Anderson, T. Bessho, M. Grätzel and B. C. O'Regan, Adv. Mater., 2013, 25, 1881-1922.

44 N. W. Duffy, L. M. Peter, R. M. G. Rajapakse and K. G. U. Wijayantha, Electrochem. Commun., 2000, 2, 658-662.

45 Y. Lin, Y. T. Ma, L. Yang, X. R. Xiao, X. W. Zhou and X. P. Li, J. Electroanal. Chem., 2006, 588, 51-58.

46 Y. Chiba, A. Islam, R. Komiya, N. Koide and L. Han, Appl. Phys. Lett., 2006, 88, 223505.

47 C. Law, L. Miseikis, S. Dimitrov, P. Shakya-Tuladhar, X. Li, P. R. F. Barnes, J. Durrant and B. C. O'Regan, Adv. Mater., 2014, 26, 6268-6273.

48 N. Papageorgiou, M. Grätzel and P. P. Infelta, Sol. Energy Mater. Sol. Cells, 1996, 44, 405-438.

49 W. Yang, N. Vlachopoulos, Y. Hao, A. Hagfeldt and G. Boschloo, Phys. Chem. Chem. Phys., 2015, 17, 1586815875.

50 H. Ellis, S. K. Eriksson, S. M. Feldt, E. Gabrielsson, P. W. Lohse, R. Lindblad, L. Sun, H. Rensmo, G. Boschloo and A. Hagfeldt, J. Phys. Chem. C, 2013, 117, 21029-21036.

51 P. R. F. Barnes, A. Y. Anderson, J. R. Durrant and B. C. O'Regan, Phys. Chem. Chem. Phys., 2011, 13, 5798.

52 J. Nissfolk, K. Fredin, J. Simiyu, L. Häggman, A. Hagfeldt and G. Boschloo, J. Electroanal. Chem., 2010, 646, 91-99. 
53 J. Nissfolk, K. Fredin, A. Hagfeldt and G. Boschloo, J. Phys. Chem. B, 2006, 110, 17715-17718.

54 F. Cao, G. Oskam, G. J. Meyer and P. C. Searson, J. Phys. Chem., 1996, 100, 17021-17027.

55 A. C. Fisher, L. M. Peter, E. A. Ponomarev, A. B. Walker and K. G. U. Wijayantha, J. Phys. Chem. B, 2000, 104, 949-958.

56 J. van de Lagemaat and A. J. Frank, J. Phys. Chem. B, 2000, 104, 4292-4294.

57 H. N. Tsao, J. Burschka, C. Yi, F. Kessler, M. K. Nazeeruddin and M. Grätzel, Energy Environ. Sci., 2011, 4, 4921.

58 H. J. Lee, P. Chen, S.-J. Moon, F. Sauvage, K. Sivula, T. Bessho, D. R. Gamelin, P. Comte, S. M. Zakeeruddin, S. Il Seok, M. Grätzel and M. K. Nazeeruddin, Langmuir, 2009, 25, 7602-7608.

59 R. Jiang and G. Boschloo, Manuscript in preparation.
60 L. M. Peter, N. W. Duffy, R. L. Wang and K. G. U. Wijayantha, J. Electroanal. Chem., 2002, 524-525, 127-136.

61 G. Boschloo, L. Häggman and A. Hagfeldt, J. Phys. Chem. B, 2006, 110, 13144-13150.

62 N. Kopidakis, N. R. Neale and A. J. Frank, J. Phys. Chem. B, 2006, 110, 12485-12489.

63 B. van der Zanden and A. Goossens, J. Phys. Chem. B, 2000, 104, 7171-7178.

64 G. Boschloo and A. Hagfeldt, J. Phys. Chem. B, 2005, 109, 12093-12098.

65 P. R. F. Barnes, A. Y. Anderson, M. Juozapavicius, L. Liu, X. Li, E. Palomares, A. Forneli and B. C. O'Regan, Phys. Chem. Chem. Phys., 2011, 13, 3547-3558.

66 B. C. O'Regan and F. Lenzmann, J. Phys. Chem. B, 2004, 108, 4342-4350. 